\title{
Iranian and Swedish Adolescents: Differences in Personality Traits and Well-Being
}

Introduction: This study addresses the need to further contextualize research on well-being (e.g., Kjell 2011) in terms of cross-cultural aspects of personality traits among adolescents and by examining two different conceptualization of well-being: subjective well-being (i.e., life satisfaction, positive and negative affect) and psychological well-being (i.e., positive relations with others, environmental mastery, self-acceptance, autonomy, personal growth, and life purpose).

Methods: Iranian ( $N=122$, mean age 15.23 years) and Swedish $(N=109$, mean age 16.69 years) adolescents were asked to fill out a Big Five personality test, as well as questionnaires assessing subjective well-being and psychological well-being.

Results: Swedes reported higher subjective and psychological well-being, while Iranians reported higher degree of Agreeableness, Openness and Conscientiousness. Neuroticism and Extraversion did not differ between cultures. Neuroticism was related to well-being within both cultures. Openness was related to well-being only among Iranians, and Extraversion only among Swedes. A mediation analysis within the Swedish sample, the only sample meeting statistical criteria for mediation analysis to be conducted, demonstrated that psychological well-being mediated the relationship between Neuroticism and subjective wellbeing as well as between Extraversion and subjective well-being.

Conclusions: Certain personality traits, such as, Extraversion, Openness, and Conscientiousness relate differently to well-being measures across cultures. Meanwhile, Neuroticism seems to relate similarly across cultures at least with regard to subjective wellbeing. Furthermore, the results give an indication on how psychological well-being might mediate the relationship between certain personality traits and subjective well-being. Overall, the complexity of the results illustrates the need for more research whilst supporting the importance of contextualizing well-being research. 
Oscar N. E. Kjell ${ }^{1 *}$, Ali A. Nima ${ }^{2,3}$, Sverker Sikström¹, Trevor Archer ${ }^{2,3}$, Danilo Garcia ${ }^{3,4,5 *}$ ${ }^{1}$ Department of Psychology, Lund University, Lund, Sweden

${ }^{3}$ Network for Empowerment and Well-Being, Sweden

$4 \quad{ }^{4}$ Center for Ethics, Law and Mental Health (CELAM), University of Gothenburg, Gothenburg,

\section{Sweden}

6 5nstitute of Neuroscience and Physiology, The Sahlgrenska Academy, University of Gothenburg, Gothenburg, Sweden

18 * Correspondence concerning this article should be addressed to ONE. Kjell, Lunds Universitet,

19 Institutionen för Psykologi, Paradisgatan 5P, 22350 Lund, Sweden. E-mail: oscar.kjell@psy.lu.se

20 and to D. Garcia, CELAM, University of Gothenburg, Wallinsgatan 8, SE 43141 Mölndal,

21 Sweden. E-mail: danilo.garcia@neuro.gu.se; danilo.garcia@euromail.se. 
22 The study of well-being during adolescence is important since this period of life is characterized

23 by various events and transitions that significantly influence adolescents' well-being (González et

24 al. 2007). Although research on adolescents' well-being has gained terrain in the last decade (e.g.,

25 see Garcia \& Archer 2012; Garcia \& Siddiqui 2009a, b; Garcia \& Sikström, 2013; Fogle et al.

26 2002; Funk III et al. 2006), the study of well-being across cultures is still scarce (for a recent

27 review showing that the majority of previous research in this area involves American participants

28 see Proctor et al. 2009). Cross-cultural research is important because indices of well-being

29 behave differently in cross-cultural comparative research (Beirens \& Fontaine 2011; Diener et al.

30 2009). Herein, cross-cultural differences between adolescents from Sweden and Iran are

31 examined in relation to differences in personality traits across cultures. Within this framework the

32 relationships between subjective well-being and psychological well-being are also explored.

33 Swedes, as compared with Iranians, tend to report higher levels of well-being in several

34 global polls (e.g., Veenhoven 2013; Diener \& Tov 2009). Notably, though, these comparisons

35 most often involve measures of subjective well-being (e.g., happiness and life satisfaction) in

36 relation to important societal variables (e.g., crime, education and health) (Veenhoven 2012)

37 rather than cross-cultural variations in psychological well-being or personality measures.

38 Importantly though, research has recently demonstrated the increasing importance of personality

39 traits and its diverse and strong influences on various aspects of well-being (Lucas \& Diener

40 2008; Kim-Prieto et al. 2005; Steel, Schmidt \& Shultz 2008). Further, in relation to global polls,

41 personality research shows that cultures that are geographically far from each other tend to

42 exhibit differences in personality traits (Allik \& McCrae 2004). There are clear differences

43 between European and American cultures as compared with Asian and African cultures:

44 Europeans and Americans, for instance, report being higher in Extraversion and Openness to

45 experience and lower in Agreeableness (Allik \& McCrae 2004). How these cross-cultural 
46 personality differences relate to well-being is important — especially considering that personality

47 is one of the most important determinants of well-being (Kim-Prieto et al. 2005). Hence, since

48 Iran and Sweden are geographically far away from each other, being positioned in Europe versus

49 Asia respectively, we expect their personality profiles to be different. Further, this expected

50 variation might address the question specifically under investigation herein: are different

51 personality traits related to different well-being conceptions across cultures.

\section{Subjective Well-being and Psychological Well-Being}

53 In the current study two distinct approaches were employed to comprehensively capture the

54 concept of well-being (for recent discussions on the benefits of employing a variety of well-being

55 measures see: Biswas-Diener et al. 2009; Delle Fave and Bassi 2009; Garcia 2013; Garcia et al.

56 2013; Kashdan et al. 2008; Ryan \& Huta 2009; Straume \& Vittersø 2012; Waterman 2008). The

57 first approach, subjective well-being (Diener, 1984), conceptualizes high well-being as the

58 assessment of individuals' own judgments of high life satisfaction, high frequency of positive

59 affect and low frequency of negative affect. The second approach, psychological well-being (Ryff

60 1989), includes 6 distinct dimensions involving: positive relations with others, environmental

61 mastery, self-acceptance, autonomy, personal growth, and life purpose. These 6 dimensions

62 define psychological well-being both theoretically and operationally, and they identify what

63 promotes effective mastery of life events and emotional and physical health (Ryff 1989).

64 Although both approaches can be seen to reflect Western cultures (e.g., Christopher, 1999); the

65 two different ways to measure well-being differ in that the psychological well-being approach

66 consist of predefined criteria (i.e., the 6 dimensions) meanwhile the subjective well-being

67 approach is comparatively more 'open' in allowing the respondents to decide the criteria for

68 themselves (although within the predefined criteria of satisfaction). Psychological well-being is

69 often theorized to promote subjective well-being (Ryan \& Deci 2001). For example, among 
70 Swedish adolescents, psychological well-being, and especially the subscale of self-acceptance, is

71 strongly related to subjective well-being (Garcia 2011a, b, 2012a; Garcia \& Archer 2012; Garcia

$72 \&$ Siddiqui 2009b). This relationship is significant even when personality traits are controlled for.

73 The current study will expand these findings by examining if psychological well-being mediates

74 the relationship between certain personality traits and subjective well-being.

\section{Personality Traits and Well-Being}

76 In the present study, personality traits are operationalized employing the Big Five Inventory 77 (Benet-Martínez \& John, 1998). This is a valid and reliable instrument measuring five 78 dimensions: Extraversion, Neuroticism, Agreeableness, Conscientiousness and Openness (for a 79 review see, John et al., 2008). Neuroticism and Extraversion appear to be most significant in 80 predicting adults' and adolescents' subjective well-being; where Extraversion tends to correlate 81 positively and Neuroticism negatively with subjective well-being (e.g., Fogle et al., 2002; Lucas, 82 2008). Extraversion seems to influence subjective well-being because it is positively related to 83 positive affect and being more attentive to positive experiences; whilst Neuroticism appears to be

84 strongly negatively related to negative affect as well as being more prone to react more intensely 85 to negative experiences (Larsen \& Eid 2008). However, Vittersø (2001) and DeNeve and Cooper 86 (1998) put forward evidence that Extraversion is overrated as a predictor of subjective well-

87 being. For example, Vittersø (2001) demonstrated that Neuroticism not only predicts the presence 88 of negative affect but also the absence of positive affect better than Extraversion. Furthermore, 89 while the influence of Neuroticism on subjective well-being appears analogous for adolescents 90 and adults (e.g., Fogle et al. 2002), recent research on adolescents yield mixed results for the trait

91 of Extraversion. For instance, Rigby and Huebner (2005) suggest that specific avoidant behavior

92 (e.g., avoiding standing out) in some adolescents might reduce the advantages of Extraversion 93 that is seen among adults (see also Garcia 2011a). Thus, meanwhile the negative relationship 
94 between Neuroticism and subjective well-being appears rather straightforward; the proposed

95 positive relationship between Extraversion and subjective well-being seems more complex.

96 Agreeableness and Conscientiousness yield small to moderate positive correlations with

97 measures of subjective well-being; whilst Openness shows no clear correlation with subjective

98 well-being (DeNeve \& Cooper 1998; Diener \& Seligman 2002; Lucas 2008). Nevertheless,

99 findings by Allik and McCrea (2004) show that certain traits are more (un)common in certain

100 cultures compared to others. The saliency or relative lack of these traits should serve a specific

101 function — for example; these specific traits could be related to well-being within that culture.

102 The discussed patterns between personality traits and subjective well-being appear to

103 overlap with the research on psychological well-being, wherein, among adults, high levels of

104 Extraversion and Conscientiousness, along with low levels of Neuroticism predict high levels of

105 psychological well-being (Ryff et al. 2002). These specific findings have also been replicated

106 among Swedish adolescents (Garcia 2011a).

\section{The Present Study}

108 The current study addresses the need to further contextualize research on well-being (e.g., see

109 Kjell 2011) in terms of cross-cultural aspects of personality traits among adolescents. We begin to

110 draw two hypotheses that are rather straightforward in the empirical literature, that is, we expect:

111 i) personality traits to vary between nationalities and ii) Swedish, as compared with Iranian,

112 adolescents to report higher scores on most dimensions of well-being. However, since current

113 research on the relationship between well-being and personality traits is, to date, somewhat scarce

114 in terms of cross-cultural variations, we are more careful in terms of these hypotheses: we expect

115 iii) personality traits to be related to the two current well-being measures, so that:

116 a. Considering the strong evidence that Neuroticism consistently is negatively related to 117 well-being measures, both Swedish and Iranian data are hypothesized to demonstrate this 
118 negative relationship. However, if these cultures show differences in other personality

119 traits; these traits are also expected to be related to well-being.

120 b. Psychological well-being will be related to subjective well-being as well as mediating the

121 relationship between personality traits and subjective well-being.

Method

\section{Participants and procedure}

124 The data was collected at a high school in south of Sweden $(N=109,38$ boys and 71 girls, mean 125 age 16.69 years $S D .91$ years $)$ and two high schools in Tehran and Zanjan, Iran $(N=122,72$ boys

126 and 50 girls, mean age 15.23 years $S D 1.26$ years). The sampling procedure of schools was based 127 on convenience and included the entire schools; although they had no particular interest or 128 knowledge about our research interest beforehand. Teachers and parents were informed about the 129 nature of the study and that participation was voluntary and that pupils had the right to withdraw 130 at any moment. The school nurse from each school was contacted by the researchers and 131 informed about the study in case any of the students needed counseling. Participants were 132 informed that the study examined how pupils think about their lives in different situations. They

133 were ensured anonymity and informed that participation was voluntary; they had consent from

134 their teachers to participate. The study was conducted in the participants' own classrooms in 135 groups of 20 to 30 pupils; the questionnaires were distributed on paper. The entire procedure, 136 including debriefing, took approximately 30 minutes. The Ethics Committee of Gothenburg 137 University approved this research protocol and written informed consent was obtained from all 138 the participants.

\section{Questionnaires}

142 The Big Five Inventory (Benet-Martínez \& John 1998) is a 44-item (5-point Likert scale: $1=$ 
143 strongly disagree to $5=$ strongly agree) instrument that enables efficient assessment of the five

144 personality dimensions: Neuroticism (e.g., I see myself as a person "who worries a lot"),

145 Extraversion (e.g., I see myself as a person "who is talkative"), Openness (e.g., I see myself as a

146 person who "is original, has new ideas"), Agreeableness (e.g., I see myself as a person who "has

147 a forgiving nature"), and Conscientiousness (e.g., I see myself as a person who "does things

148 efficiently"). This self-report measure has been empirically demonstrated to be apt for cross-

149 language and cross-cultural research (Benet-Martínez \& John 1998; Allik \& McCrae 2004). For

150 the Swedish sample the instrument was translated from English to Swedish and then

151 backtranslated by Swedish native speakers; no significant discrepancies were found. Cronbach's

$152 \alpha$ varied between .84 and .92 among traits. The Iranian version has been used in previous studies

153 (e.g., Joshanloo \& Afshari 2009; Joshanloo \& Nosratabadi 2009). For the Iranian version

154 Cronbach's $\alpha$ varied between .65 and .72 in the present study.

The Satisfaction With Life Scale (Diener et al. 1985) assesses the cognitive component of

156 subjective well-being (i.e., life satisfaction) and consists of 5 items (e.g., "In most of my ways my

157 life is close to my ideal") that require a response on a 7-point Likert scale $(1=$ strongly disagree,

1587 = strongly agree). Both the Swedish and the Iranian versions of this instrument have previously

159 been used in these cultures (e.g., Garcia 2011c, 2012; Garcia et al. 2011; Garcia \& Moradi 2012,

160 2013; Jokar et al. 2007; Joshanloo \& Ghaedi 2009). In the current study the instrument had a

161 Cronbach's $\alpha=.83$ in the Swedish sample and .87 in the Iranian sample.

162 The Positive Affect and Negative Affect Schedule (Watson et al. 1988) assesses the

163 affective components of subjective well-being by requiring participants to indicate on 5-point

164 Likert scale to what extent $(1=$ very slightly, $5=$ extremely) they generally experienced 20

165 different adjectives (10 positive affect and 10 negative affect) within the last few weeks. The

166 positive affect scale includes adjectives such as strong, proud, and interested; and the negative 
167 affect scale includes adjectives such as afraid, ashamed, and nervous. The Swedish version has

168 been used in previous studies (e.g., Garcia et al. 2012a, b, c; Garcia \& Erlandsson 2011; Garcia et 169 al. 2010; Nima et al. 2012; Nima, Rosenberg, Archer \& Garcia, 2013; Schütz, Archer \& Garcia,

170 2013) and demonstrated good internal consistency in the present study (positive affect

171 Cronbach's $\alpha=.86$, negative affect Cronbach's $\alpha=.78$ ). The Iranian version was translated from

172 English to Farsi and backtranslated by Farsi native speakers; no significant discrepancies were

173 found. The Iranian version demonstrated low but acceptable internal consistence; Cronbach's $\alpha$ $174=.56$ for positive affect and .57 for negative affect.

18 items, 3 items for each of the 6 dimensions, using a 6-point Likert scale $(1=$ strongly disagree,

1776 = strongly agree). These dimensions are: (i) positive relations with others (e.g., "People would

178 describe me as a giving person, willing to share my time with others"), (ii) environmental

179 mastery (e.g., " I am quite good at managing the responsibilities of my daily life"), (iii) self-

180 acceptance (e.g., "I like most aspects of my personality”), (iv) autonomy (e.g., "I have confidence

181 in my own opinions, even if they are contrary to the general consensus"), (v) personal growth 182 (e.g., "For me, life has been a continuous process of learning, changing, and growth"), and (vi)

183 purpose in life ("Some people wander aimlessly through life, but I am not one of them"). The

184 Swedish version has been used in previous studies (e.g., Garcia 2011a; Garcia \& Siddiqui 2009b;

185 Nima et al. 2013) and in the current study the total psychological well-being score (i.e., the sum 186 of the 18 items) demonstrated a Cronbach's $\alpha$ of .72. The Iranian version has also been used in 187 several studies (e.g., Garcia \& Moradi 2013; Joshanloo \& Ghaedi 2009) and in the current study 188 the total psychological well-being score demonstrated a Cronbach's $\alpha$ of .62.

\section{Results}

190 The initial analyses examine differences in personality traits, subjective well-being and 
191 psychological well-being between the national samples by employing three Multivariate Analyses

192 of Variance (MANOVA). Thereafter the relationship between personality as a predictor of well-

193 being is examined by means of regression analyses within each sample; which further allows for

194 the use of mediational analyses.

\section{Differences between Swedish and Iranian Adolescents}

196 Table 1 shows mean scores and standard deviations as well as indicating significant differences

197 for all variables in both samples. Independent factors for all MANOVAs were nationality and

198 gender. For the first MANOVA the dependent factors were the Big Five personality traits, for the

199 second, the three components of subjective well-being, and for the third, the six dimensions of

200 psychological well-being and its' total score.

The first MANOVA showed that nationality $(F(5,192)=15.27, p<.001$, Wilks' Lambda

$202=.72$, Observed Power $=1.00)$ and gender $(F(5,192)=6.05, p<.001$, Wilks' Lambda $=.86$,

203 Observed Power $=1.00$ ) had an effect on the personality traits. The interaction of nationality and

204 gender was also significant $(F(5,192)=2.91, p<.01$, Wilks' Lambda $=.93$, Observed Power $=$.

205 84). Iranian adolescents scored significantly higher in Agreeableness $(F(1,196)=6.41, p<.01$,

206 Observed Power $=.71)$, Openness $(F(1,196)=18.89, p<.001$, Observed Power $=1.00)$ and

207 Conscientiousness $(F(1,196)=12.17, p<.001$, Observed Power $=.94)$. Overall, the national

208 samples did not differ significantly in Extraversion and Neuroticism; however, Swedish boys

209 scored significantly lowest and Swedish girls scored significantly higher in Neuroticism

$210(F(1,196)=9.03, p<.001$, Observed Power $=.99)$. See Table 1 for more details.

211 The second MANOVA showed that nationality $(F(3,201)=12.23, p<.001$, Wilks'

212 Lambda $=.85$, Observed Power $=1.00$ ) had a significant effect on the subjective well-being

213 measures. Although the effect of gender was not significant $(p=.20)$, the interaction of

214 nationality and gender was significant $(F(3,201)=20.48, p<.001$, Wilks' Lambda $=.77$, 
215 Observed Power $=1.00)$. Swedish adolescents reported higher positive affect $(F(1,203)=12.02$,

$216 p<.001$, Observed Power $=.93)$ and lower negative affect $(F(1,203)=26.29, p<.001$, Observed

217 Power $=1.00)$ than Iranian adolescents. Of all the groups, Iranian boys reported lowest positive

218 affect and highest negative affect (see Table 1). No difference in life satisfaction was found

219 between cultures and the interaction of nationality and gender had no effect on life satisfaction 220 either.

221

The third MANOVA showed that nationality $(F(6,191)=14.24, p<.001$, Wilks' Lambda

222

$=.69$, Observed Power $=1.00)$ and gender $(F(1,191)=6.21, p<.001$, Wilks' Lambda $=.84$,

223

Observed Power $=1.00$ ) had a significant effect on the psychological well-being measures. The

224

interaction of nationality and gender was also significant $(F(6,191)=4.37, p<.001$, Wilks'

225

Lambda $=.88$, Observed Power $=1.00)$. Swedish adolescents scored higher on positive relations

226

$(F(1,196)=11.79, p<.001$, Observed Power $=.93)$, personal growth $(F(1,196)=38.35, p<$.

227

001, Observed Power $=1.00)$, Purpose in Life $(F(1,196)=5.87, p<.001$, Observed Power $=$.

228

$67)$, and the psychological well-being total score $(F(1,196)=4.28, p<.05$, Observed Power $=$.

229

54). Iranian adolescents scored higher on autonomy $(F(1,196)=28.32, p<.001$, Observed Power

$230=1.00)$. Moreover, boys as a group scored higher on environmental mastery $(F(1,196)=15.36, p$

$231<.001$, Observed Power $=.97)$. The interaction of nationality and gender was significant for the

232 psychological well-being total score $(F(1,196)=5.65, p<.01$, Observed Power $=.66)$ and self-

233 acceptance $(F(1,196)=15.83, p<.001$, Observed Power $=.98)$. Specifically, Swedish boys

234 reported higher scores on both psychological well-being total score and self-acceptance. Iranian 235 girls reported higher self-acceptance than Iranian boys (see Table 1)

Table 1 should be about here

237 Relationships between Personality and Well-Being within Samples

238 Swedish Adolescents: Table 2 displays the correlations between personality and well-being 
239 variables for the Swedish sample. Multiple Regression Analysis (MRA) showed that Extraversion

240 was positively related to life satisfaction; Neuroticism was negatively related to life satisfaction

241 and positive affect and positively related to negative affect (see Table 3). Neuroticism,

242 Extraversion, and Conscientiousness were associated to the psychological well-being total score.

243 Among the six psychological well-being dimensions, Neuroticism was negatively associated and

244 Extraversion was positively associated to positive relations (see also Agreeableness which was

245 positively associated to this psychological well-being dimension), environmental mastery (see

246 also Conscientiousness which was positively associated to this psychological well-being

247 dimension), self-acceptance, and autonomy. Personal growth was positively associated to the

248 traits of Conscientiousness and Openness, while purpose in life was solely positively associated

249 to Conscientiousness (see Table 2).

250 Each of the six dimensions of psychological well-being were related to at least one of

251 the subjective well-being measures: life satisfaction was positively related to self-acceptance,

252 positive affect was positively related to environmental mastery and self-acceptance but negatively

253 related to positive relations with others, and negative affect was negatively related to

254 environmental mastery. See Table 2 for details.

255

256

257

258

259

260

261

262 $\underline{\text { Insert Table } 2 \text { about here }}$

Insert Table 3 about here

Iranian Adolescents: Table 4 displays the correlations between personality and wellbeing variables for the Iranian sample. In accord with the Swedish sample and our hypothesis, the MRA for the Iranian data showed that Neuroticism was negatively related to life satisfaction and positively related to negative affect. In contrast to the results among Swedes, Neuroticism was not associated to positive affect and Extraversion was not related to any subjective well-being measure (see Table 5). Instead, Openness was positively related to life satisfaction and positive 
263 affect. The only psychological well-being dimensions related to personality traits among Iranian

264 adolescents were personal growth (positively related to Extraversion) and purpose in life

265 (positively related to Openness). Also, in contrast to the results among Swedish adolescents, only

266 self-acceptance was positively related to life satisfaction and positive affect. negative affect was

267 not associated to any of the six psychological well-being dimensions. See Table 5 for details.

Table 4 should be about here

269

Table 5 should be about here

Mediation Analyses between Personality traits, subjective well-being and psychological

well-being

272 We conducted mediation analyses applying procedures recommended by Baron and Kenny

273 (1986) to test if the effect of personality on subjective well-being was mediated by psychological

274 well-being. For this specific analysis we created a subjective well-being total score by first

275 standardizing positive affect, negative affect, and life satisfaction, and then subtracting the

276 standardized negative affect score from the standardized positive affect score and finally

277 summarizing life satisfaction (i.e., (zpositive affect - znegative affect) + zlife satisfaction).

278 Personality variables were set to be the predictors, the psychological well-being total score as the

279 mediator and subjective well-being total score as the outcome variable. Importantly, as

280 recommended by Baron and Kenny (1986), only personality traits that significantly predicted the

281 outcome variable (i.e., subjective well-being) and the mediator (i.e., psychological well-being)

282 were used in the analyses. For the Swedish sample, Extraversion and Neuroticism met these

283 criteria. However, although Openness and Neuroticism predicted subjective well-being in the

284 Iranian sample, neither of the traits predicted psychological well-being in this sample. Hence,

285 mediation analyses could only be conducted for the Swedish sample.

286 A series of equations were conducted for analyzing the associations between personality 
287 (predictor variable), psychological well-being (mediator), and subjective well-being (outcome

288 variable) within the Swedish dataset. Firstly, psychological well-being was regressed on

289 Extraversion and Neuroticism. Both Extraversion (positively: $\beta=.28, t=3.30, p<.001$ ) and

290 Neuroticism (negatively: $\beta=.-53, t=-6.17, p<.001$ ) were related to psychological well-being.

291 Secondly, applying hierarchal regression, subjective well-being was regressed on Extraversion

292 and Neuroticism in the first step and to psychological well-being in the second step. In the first

293 step Extraversion $(\beta=.26, t=2.82, p<.01)$ and Neuroticism $(\beta=-.51, t=-5.40, p<.001)$ were

294 significantly associated with subjective well-being. In the second step, the effect of Extraversion

295 on subjective well-being was no longer significant $(\beta=-.18, t=1.90, p=.06)$ while Neuroticism

296 was still associated with subjective well-being $(\beta=-.33, t=-3.01, p=.004)$. Moreover, in the

297 second step of the regression, psychological well-being was associated with subjective well-being

$298(\beta=.33, t=2.94, p=.004)$ and even increasing the prediction of the model $\left(\Delta R^{2}=.06, F(1,75)\right.$

$299=8.62, p=.004)$. Psychological well-being yielded a Sobel Z-value $=1.80(p=.07)$ for the

300 relationship Extraversion-psychological well-being-subjective well-being and a Sobel Z-value =

$3012.08(p<.05)$ for the relationship Neuroticism-psychological well-being-subjective well-being

302 (see Figure 1). In other words, these reductions in beta weights suggest that psychological well-

303 being serves to partially mediate the relationship between Extraversion and subjective well-being

304 and the relationship between Neuroticism and subjective well-being.

Figure 1 should be about here

\section{Discussion}

307 The current study investigated variations in well-being in the context of cross-cultural personality

308 traits among adolescents. In accordance with previous studies (e.g., Veenhoven 2013; Diener \&

309 Tov 2009), Swedish participants reported higher overall well-being than Iranian participants.

310 Furthermore, personality profiles differed significantly between cultures. In accordance with 
311 other studies among adults (e.g., Allik \& McCrae 2004), Iranian adolescents reported higher

312 Agreeableness than Swedish adolescents. Further, the Iranian adolescents also reported higher

313 Conscientiousness and Openness than Swedish adolescents. The cultures, however, did not differ

314 significantly in Extraversion and Neuroticism; although, notably Swedish boys reported

315 significantly lower and Swedish girls reported significantly higher levels of Neuroticism than all

316 other groups.

317 Importantly, the present analyses also indicated that cultural variations in self-reported

318 personality traits appear to, in part, be related to differences in well-being. The analyses revealed

319 that in the Swedish sample, Extraversion was positively related to most measures of well-being,

320 and that Conscientiousness was positively related to three of the six psychological well-being

321 dimensions: environmental mastery, personal growth, and purpose in life. This is in accordance

322 with research illustrating that adolescents who are goal-directed and self-controlled (or showing a

323 high degree of agency, which the three psychological well-being dimensions might be argued to

324 tap into; Schütz, Sailer, Nima, Rosenberg, Andersson Arntén, Archer \& Garcia, 2013) are found

325 to also report high levels of well-being (Garcia 2011a, 2012b). In the Iranian sample, in contrast,

326 Openness (rather than Extraversion) was positively related to three well-being measures: life

327 satisfaction, positive affect, and purpose in life.

Interestingly, the Iranian adolescents scored significantly higher on Openness and it was,

329 only for them, Openness was positively associated with well-being. At the same time, Swedish

330 and Iranian adolescents did not differ in Extraversion whilst this trait was only positively

331 associated with well-being within the Swedish sample. Conscientiousness was higher represented

332 in Iran but related to well-being within the Swedish sample. Hence, this partially supports our

333 hypothesis, demonstrating that different personality traits can have different influences on well-

334 being in different cultures. However, with the exception of Openness among Iranians, these 
335 associations seem to not depend on whether specific personality traits are being salient in the 336 culture.

337 In terms of notable similarities between the two cultures, the psychological well-being 338 dimension of self-acceptance was positively related to high subjective well-being in both 339 samples. This specific result is in accordance to earlier findings regarding adolescents' subjective 340 well-being (e.g., Garcia \& Siddiqui 2009b; Garcia 2011b, 2012a). That is, adolescents who are 341 satisfied with their lives and experience more positive than negative affect seem to be acceptant 342 of all parts of their personality. This specific attitude to the self might be adaptive because it 343 allows the individual to be aware of the self without judging some characteristics as negative or 344 positive, non-evaluative self-awareness is indeed an important factor for well-being (Cloninger 345 2004, 2006; Cloninger \& Zohar 2011; Garcia, Anckarsäter \& Lundström, 2013; Garcia, 346 Lundström, Brändström, Råstam, Cloninger, Kerekes, Nilsson \& Anckarsäter, 2013; Garcia, 347 Nima, Archer, 2013).

Further, Neuroticism was related to a wide range of well-being dimensions in both 349 cultures; in the Swedish sample it was associated with all subjective well-being components (i.e., 350 negatively related to life satisfaction and positive affect, and positively related to negative affect) 351 and psychological well-being (i.e., negatively related to psychological well-being total score, 352 positive relations, environmental mastery, self-acceptance, and autonomy). Similarly in the 353 Iranian sample, with the exception of positive affect, Neuroticism was negatively related to life 354 satisfaction and positively related to negative affect. Altogether, the strong relationship between 355 Neuroticism and subjective well-being lends important support for the high relevance of 356 Neuroticism put forward by Vittersø (2001), among others. However, Neuroticism was not 357 significantly associated with psychological well-being in the Iranian sample. In addition, as 358 earlier described, a difference between the samples is that Swedish boys reported significantly 
359 lower and Swedish girls reported significantly higher levels of Neuroticism than all other groups.

360 Hence this gender difference across cultures might be worth scrutinizing in future research.

\section{Limitations}

362 This study was based on self-reported data and correlational methods that ought to be replicated

363 and supported with other methods such as experimental studies. Further, considering the rather

364 small size of both samples, cautiousness in generalizing the results is warranted as well as

365 acknowledging the need for replicating the core purposes of the study. Nevertheless, with the

366 exception of the differences between the samples in purpose in life and psychological well-being

367 total score, the Observed Power was between .84-1.00 - an Observed Power of .80 is generally

368 considered acceptable (Cohen, 1988). It is also important to note that the use of current well-

369 being measures can be seen to mirror Western cultures' conceptions of well-being and might not

370 necessarily be equally suited for Eastern Muslim samples (Joshanloo 2012). Perhaps, explaining

371 the substantial difference in reliability of used scales between the two samples. To address this in

372 future research might involve a re-conceptualization of well-being and the development of new

373 culturally sensitive scales (Joshanloo 2012). Nonetheless, these results make up an initial

374 platform to build further research upon.

375 Unfortunately the Iranian data set did not allow for the mediation analyses because the

376 statistical criteria for such analyses put forward by Baron and Kenny (1986) were not met.

377 Perhaps this is related to the cultural differences in the conceptions of well-being discussed

378 above. Nevertheless, within the Swedish sample, mediation analyses revealed that psychological

379 well-being mediated the relationship between both Neuroticism and Extraversion, to subjective

380 well-being. Hence, this lends empirical support that psychological well-being promote subjective

381 well-being as theorized by Ryan and Deci (2001), among others.

\section{Conclusions}


383 The current study is an addition to previous research showing that Swedes overall tend to report

384 higher well-being than Iranians. Certain personality traits, such as, Extraversion, Openness, and

385 Conscientiousness relate differently to subjective well-being and psychological well-being among

386 adolescents in these two cultures. Meanwhile, Neuroticism seems to relate similarly across

387 cultures; at least with regard to subjective well-being. Furthermore, the results give an indication

388 on how psychological well-being might mediate the relationship between certain personality

389 traits and subjective well-being. Overall, to achieve a comprehensive understanding of the

390 relationship between personality and well-being, the current results support the importance of

391 contextualizing well-being research at the same time as also employing various well-being

392 measures.

393 "Personality goes a long way"

394 Jules in Pulp Fiction

397 Acknowledgments

398 The authors are indebted to the participants for their help in facilitating the study and to Patricia

399 Rosenberg, Saleh Moradi, Reza Molaei, Hasan Kiaei, and Azar Taheri for assistance with the 400 Swedish and Iranian data.

401 


\section{References}

403

404

405

406

407

408

409

410

411

412

413

414

415

416

417

418

419

420

421

422

423

424

425

426

Allik, J, \& McCrae, RR (2004). Toward a Geography of Personality Traits: Patterns of Profiles across 36 Cultures. Journal of Cross-Cultural Psychology, 35, 13-28. DOI: 10.1177/0022022103260382.

Baron, RM, \& Kenny, DA (1986). The moderator-mediator variable distinction in social psychological research: Conceptual, strategic, and statistical considerations. Journal of Personality and Social Psychology, 51, 1173-1182. DOI: 10.1037/0022-3514.51.6.1173

Beirens, K, \& Fontaine, JRJ (2011) Somatic and Emotional Well-Being Among Turkish Immigrants in Belgium: Acculturation or Culture? Journal of Cross-Cultural Psychology, 42, 56-74. DOI: $10.1177 / 0022022110361773$.

Benet-Martínez,V, \& John, OP (1998). Los cinco grandes across cultures and ethnic groups: Multitrait multimethod analysis of the Big Five in Spanish and English. Journal of Personality and Social Psychology, 75, 729-750. DOI: 10.1037/0022-3514.75.3.729

Biswas-Diener, R, Kashdan, T, \& King, LA (2009). Two traditions of happiness research, not two distinct types of happiness. Journal of Positive Psychology, 4, 208-211.

Clarke, PJ, Marshall, VM, Ryff, CD, \& Wheaton, B (2001). Measuring psychological well-being in the Canadian study of health and aging. International Psychogeriatrics, 13, 79-90. DOI: $10.1017 / \mathrm{S} 1041610202008013$

Cloninger, CR (2004). Feeling good: The science of well-being. New York: Oxford University Press.

Cloninger, CR (2006). Fostering spirituality and well-being in clinical practice. Psychiatric Annals, 36, 1-6.

Cloninger, CR, \& Zohar, AH (2011). Personality and the perception of health and happiness. Journal of Affective Disorders, 128, 24-32. DOI: 10.1016/j.jad.2010.06.012

Cohen, J. (1988). Statistical power analysis for the behavioral sciences ( $2^{\text {nd }}$ ed.). Hillsdale, NJ: 
Erlbaum.

428 Costa, PTJr, \& McCrae, RR (1992). Revised NEO Personality Inventory (NEO-PI-R) and NEO

429 Five-Factor Inventory (NEO-FFI) manual. Odessa, FL: Psychological Assessment

$430 \quad$ Resources.

431 Christopher, J. C. (1999). Situating Psychological Well-Being: Exploring the Cultural Roots of Its 432 Theory and Research. Journal of Counseling \& Development, 77, 141-152.

433 Delle Fave, A, \& Bassi, M (2009): The contribution of diversity to happiness research, The 434 Journal of Positive Psychology, 4, 205-207. DOI: 10.1080/17439760902844319

435 DeNeve, KM, \& Cooper H (1998). The happy personality: a meta-analysis of 137 personality 436 traits and subjective well-being. Psychological Bulletin, 124,197-229. DOI: 10.1037/0033-2909.124.2.197

Diener, E (1984). Subjective well-being. Psychological Bulletin, 95, 542-575. DOI: 10.1037//0033-2909.95.3.542

Diener, E, Glatzer, W, Moum, T, Sprangers, MAG, Vogel, J, Veenhoven, R (2009). Culture and Well-Being. The collected works of Ed Diener. London: Springer. Journal of Personality Assessment, 49, 71-75. DOI: 10.1207/s15327752jpa4901_13

Diener, E, \& Seligman, MEP (2002). Very happy people. Psychological Science, 13, 81-84.

445 Diener, E, \& Tov, W (2009). Culture and Subjective Well-Being. In E. Diener, W. Glatzer, T. 446 Moum, M. A. G. Sprangers, J. Vogel, R. Veenhoven (eds.). Culture and Well-Being. The collected works of Ed Diener (pp. 9-42) London: Springer.

448 Fogle, LM, Huebner, ES, \& Laughlin, JE (2002). The relationship between temperament and life 449 satisfaction in early adolescence: Cognitive and behavioral mediation models. Journal of Happiness Studies, 3, 373-392.

451 Funk III, BA, Huebner, ES, \& Valois, RF (2006). Reliability and validity of a brief life 
satisfaction scale with a high school sample. Journal of Happiness Studies, 7, 41-54. DOI:

454 Garcia, D (2011a). Two Models of Personality and Well-Being among Adolescents. Personality and Individual Differences, 50, 1208-1212. DOI: 10.1016/j.paid.2011.02.009.

Garcia, D (2011b) Adolescents' happiness: The role of the affective temperament model on memory and apprehension of events, subjective well-being, and psychological well-being. Ph.D. Thesis, University of Gothenburg, Gothenburg.

Garcia, D (2011c). Happy Today, Happy Tomorrow: The (Non-)Effect of Temporal Distance on Life Satisfaction. Personality and Individual Differences, 51, 1048-1051. DOI: 10.1016/j.paid.2011.07.031.

Garcia, D (2012a). The Affective Temperaments and Self-Acceptance: Adolescents' Life Satisfaction and Psychological Well-Being. In M. Vassar (Ed.), The Psychology of Life Satisfaction, (pp. 1-17). New York: Nova Science Publishers.

Garcia, D (2012b). The Affective Temperaments: Differences between Adolescents in the Big Five Model and Cloninger's Psychobiological Model of Personality. Journal of Happiness Studies, 6, 999-1017. DOI: 10.1007/s10902-011-9303-5.

Garcia, D. (2013). La vie en Rose: High Levels of Well-Being and Events Inside and Outside Autobiographical Memory. Journal of Happiness Studies. DOI: 10.1007/s10902-0139443-x.

Garcia, D., Anckarsäter, H., \& Lundström, S. (2013). Self-directedness and Cooperativeness,

474 Garcia, D, \& Archer, T (2012). Adolescent Life Satisfaction and Well-Being. Journal of 475 Alternative Medicine Research, 4, 271-279.

476 Garcia, D, Archer, T, Moradi, S, \& Andersson-Arntén, A-C (2012c). Exercise Frequency, High 

Occupation. Psychology, 3, 328-336. DOI: 10.4236/psych.2012.32040.

479 Garcia, D, \& Erlandsson, A (2011). The Relationship between Personality and Subjective WellBeing: Different Association Patterns when Measuring the Affective Component in Frequency and Intensity. Journal of Happiness Studies, 12, 1023-1034. DOI:

Garcia, D, Kerekes, N, Andersson-Arntén, A-C, \& Archer, T (2012a). Temperament, Character, and Adolescents' Depressive Symptoms: Focusing on Affect. Depression Research and

Garcia, D, Ghiabi, B, Moradi, S, Siddiqui, A, \& Archer, T (2013). The Happy Personality: A Tale of Two Philosophies. In E. F. Morris \& M-A. Jackson (Eds.), Psychology of Personality (pp. 41-59). New York: Nova Science Publishers.

Garcia, D, Kerekes, N, \& Archer, T (2012b). A Will and a Proper Way Leading to Happiness: Self-Directedness Mediates the Effect of Persistence on Positive Affectivity. Personality and Individual Differences, 53, 1034-1038. DOI: 10.1016/j.paid.2012.07.025.

Garcia, D., Lundström, S., Brändström, S., Råstam, M., Cloninger, C. R., Kerekes, N., Nilsson, T., Anckarsäter, H. (2013). Temperament and Character in the Child and Adolescent Twin Study in Sweden (CATSS): Comparison to the General Population, and Genetic Structure Analysis. PLoS ONE 8(8): e70475. DOI: 10.1371/journal.pone.0070475.

Garcia, D, \& Moradi, S (2012) Adolescents' Temperament and Character: A Longitudinal Study on Happiness. Journal of Happiness Studies, 13, 931-946. DOI: 10.1007/s10902-0119300-8.

Garcia, D., \& Moradi, S. (2013). The Affective Temperaments and Well-Being: Swedish and $500 \quad$ Iranian Adolescents' Life Satisfaction and Psychological Well-Being. Journal of 501 Happiness Studies, 14, 689-707. DOI: 10.1007/s10902-012-9349-z. 
502 Garcia, D., Nima, A. A., \& Archer, T. (2013). International note: Temperament and Character's

503 Relationship to Subjective Well-Being in Salvadorian Adolescents and Young Adults.

$504 \quad$ Journal of Adolescence, 36, 1115-1119. DOI: 10.1016/j.adolescence.2013.08.018.

505 Garcia, D, Rosenberg, P, Erlandsson, A, \& Siddiqui, A (2010). On Lions and Adolescents:

506 Affective Temperaments and the Influence of Negative Stimuli on Memory. Journal of

507 Happiness Studies, 11, 477 - 495. DOI: 10.1007/s10902-009-9153-6.

508 Garcia, D, Rosenberg, P, \& Siddiqui, A (2011). Tomorrow I Could Be in Trouble...But The Sun

509 Will Come Out Next Year: The Effect of Temporal Distance on Adolescents' Judgments

$510 \quad$ of Life Satisfaction. Journal of Adolescence, 34, 751-757. DOI:

$511 \quad$ 10.1016/j.adolescence.2010.08.006.

512 Garcia, D, \& Siddiqui, A (2009a). Adolescents’ Affective Temperaments: Life Satisfaction,

513 Interpretation and Memory of events. The Journal of Positive Psychology, 4, $155-167$.

$514 \quad$ DOI: $10.1080 / 17439760802399349$.

515 Garcia, D, \& Siddiqui, A (2009b). Adolescents' Psychological Well-Being and Memory for Life

516 Events: Influences on Life Satisfaction with Respect to Temperamental Dispositions.

517 Journal of Happiness Studies, 10, 387 - 503. DOI: 10.1007/s10902-008-9096-3.

518 Garcia, D., \& Sikström, S. (2013). Quantifying the Semantic Representations in Adolescents'

519 Memories of Positive and Negative Life Events. Journal of Happiness Studies, 14, 1309-

520 1323. DOI: $10.1007 / \mathrm{s} 10902-012-9385-8$.

521 González, M, Casas, F, \& Coenders, G (2007). A complexity approach to psychological well-

522 being in adolescence: Major strengths and methodological issues. Social Indicators

523 Research, 80, 267-295. DOI: 10.1007/s11205-005-5073-y

524 John, OP, Naumann, LP, \& Soto, CJ (2008). Paradigm Shift to the Integrative Big-Five Trait

525 Taxonomy: History, Measurement, and Conceptual Issues. In O. P. John, R. W. Robins, \&

526 L. A. Pervin (Eds.), Handbook of personality: Theory and research (pp. 114-158). New 
528 Jokar, B, Samani, S, \& Sahragard, N (2007). Resilience, psychological health, and life satisfaction. Journal of Psychiatric and Clinical Psychology of Iran, 50, 290-295.

530 Joshanloo, M (2012). A comparison of Western and Islamic Conceptions of Happiness. Journal of Happiness Studies. DOI: 10.1007/s10902-012-9406-7

532 Joshanloo, M, \& Afshari, S (2009). Big five personality traits and self-esteem as predictors of life satisfaction in iranian muslim university students. Journal of Happiness Studies, 12, 105 -

Joshanloo, M, \& Ghaedi, G (2009) Value priorities as predicators of hedonic and eudaimonic aspects of well-being. Personality and Individual Differences, 47, 294-294. DOI:

Joshanloo, M, \& Nosratabadi, M (2009). Levels of mental health continuum and personality traits. Social Indicators Research, 90, 211-224. DOI: 10.1007/s11205-008-9253-4

Kashdan, TB, Biswas-Diener, R, \& King, LA (2008). Reconsidering happiness: the costs of distinguishing between hedonics and eudaimonia. The Journal of Positive Psychology, 3,

543 Kim-Prieto, C, Diener, E, Tamir, M, Scollon, C, \& Diener, M (2005). Integrating the diverse definitions of happiness: A time-sequential framework of subjective well-being. Journal

546 Kjell, ONE (2011). Sustainable Well-Being: A Potential Synergy Between Sustainability and Well-Being Research. Review of General Psychology, 15, 255-266. DOI:

549 Larsen, RJ, \& Eid, M (2008). The science of subjective well-being. New York: Guilford Press. 550 Lucas, RE (2008). Personality and subjective well-being. In R. J. Larsen \& M. Eid (Eds.), The science of subjective well-being (pp. 171-194). New York: Guilford Press. 
552 Lucas, RE, \& Diener, E (2008). Personality and Subjective Well-Being. In O. P. John, R. W. 814). New York: The Guilford Press.

555 Nima, AA, Archer, T, \& Garcia, D (2012). Adolescents' happiness-increasing Strategies,

556 Temperament, and Character: Mediation models on Subjective Well-Being. Health, 4, 802-810. DOI: 10.4236/health.2012.410124.

Nima, A. A., Archer, T., \& Garcia, D. (2013). The Happiness-Increasing Strategies Scales in a Sample of Swedish Adolescents. International Journal of Happiness and Development, 1, 196-211. DOI: 10.1504/IJHD.2013.055647

561 Nima, A. A., Rosenberg, P., Archer, T., \& Garcia, D. (2013). Anxiety, Affect, Self-Esteem, and Stress: Mediation and Moderation Effects on Depression. PLoS ONE 8(9): e 73265. DOI:10.1371/journal.pone.0073265.

Proctor, CL, Linley, A, \& Maltby, J (2009). Youth Life Satisfaction: A Review of the Literature. Journal of Happiness Studies, 10, 583-630. DOI: 10.1007/s10902-008-9110-9.

566 Rigby, BT, \& Huebner, ES (2005). Do causal attributions mediate the relationship between personality characteristics and life satisfaction in adolescence? Psychology in the Schools, 42, 91-99. DOI: 10.1002/pits.20026

Ryan, RM, \& Deci, EL (2001). On happiness and human potentials: A review of research on hedonic and eudaimonic well-being. Annual Review of Psychology, 52, 141-166. DOI: 10.1146/annurev.psych.52.1.141

572 Ryan, RM, \& Huta, V (2009). Wellness as healthy functioning or wellness as happiness: The Importance of Eudaimonic Thinking. The Journal of Positive Psychology: Dedicated to $574 \quad$ furthering research and promoting good practice, 4 , 202-204 . DOI: $10.1080 / 17439760902844285$

576 Ryff, CD (1989). Happiness is everything, or is it? Explorations on the meaning of psychological 
well-being. Journal of Personality and Social Psychology, 57, 1069-1081. DOI:

579 Ryff, CD, Keyes, CLM, \& Shmotkin, D (2002). Optimizing well-being: the empirical encounter of two traditions. Journal of personality and Social Psychology, 82, 1007-1022. DOI: $10.1037 / / 0022-3514.82 .6 .1007$

582 Steel, P., Schmidt, J., \& Shultz, J. (2008). Refining the relationship between personality and subjective well-being. Psychological Bulletin, 134, 138-161. DOI: 10.1037/00332909.134.1.138

Straume, LV, \& Vittersø, J (2012). Happiness, inspiration and the fully functioning person: Separating hedonic and eudaimonic well-being in the workplace. The Journal of Positive

Schütz, E., Archer, T. \& Garcia, D. (2013). Character Profiles and Adolescents' Self-reported Affect. Personality and Individual Differences, 54, 841-844. DOI: 10.1016/j.paid.2012.12.020.

Schütz, E., Sailer, U., Nima, A., Rosenberg, P., Andersson Arntén, A-C., Archer, T., \& Garcia, D. (2013). The affective profiles in the USA: happiness, depression, life satisfaction, and happiness- increasing strategies. PeerJ 1:e156. DOI 10.7717/peerj.156.

Veenhoven, R (2012). Cross-national differences in happiness: Cultural measurement bias or 596 effect of culture? International Journal of Wellbeing, 2(4), 333-353. DOI:10.5502/ijw.v2.i4.4

598 Veenhoven, R (2013)Happiness in NationsWorld Database of Happiness, Erasmus University Rotterdam, The Netherlands Assessed on (January $17^{\text {th }}$ ) at: http://worlddatabaseofhappiness.eur.nl/hap_nat/nat fp.php?mode $=1$

601 Vitterso, J (2001). Personality traits and subjective well-being: Emotional stability, not 
602 extraversion, is probably the important predictor. Personality and Individual Differences, $603 \quad 31(6), 903-914$.

604 Waterman, AS (2008). Reconsidering happiness: A eudaimonist's perspective. The Journal of 605 Positive Psychology: Dedicated to furthering research and promoting good practice, 3, 606 234-252. DOI: $10.1080 / 17439760802303002$

607 Watson, D, Clark, LA, \& Tellegen, A (1988). Development and validation of brief measures of 608 positive and negative affect: The PANAS scale. Journal of Personality and Social 609 Psychology, 54, 1063-1070. DOI: 10.1037/0022-3514.54.6.1063 


\section{Figure 1}

Model of the mediating role of psychological well-being in the relationships between Neuroticism and subjective well-being and between Extraversion and subjective wellbeing among Swedish adolescents.

Values in parentheses are the reduced beta weights when the mediator (i.e., psychological well-being) is present. Note: ${ }^{*} p<.05,{ }^{* *} p<.01,{ }^{* *} p<.001, n s=$ non-significant.

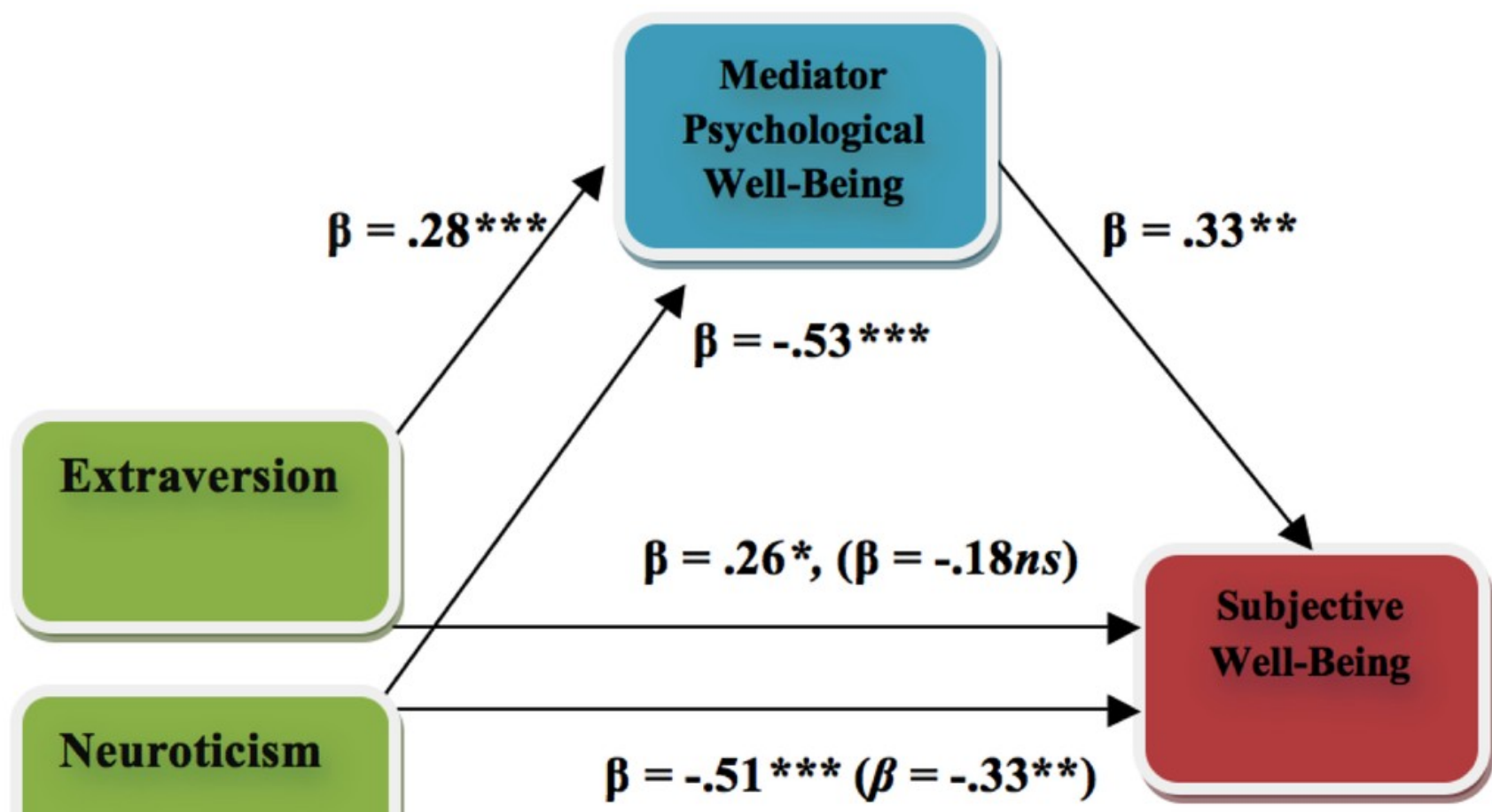




\section{Table 1 (on next page)}

Mean scores for all variables in the study in both samples. 
1 Table 1. Mean scores for all variables in the study in both samples.

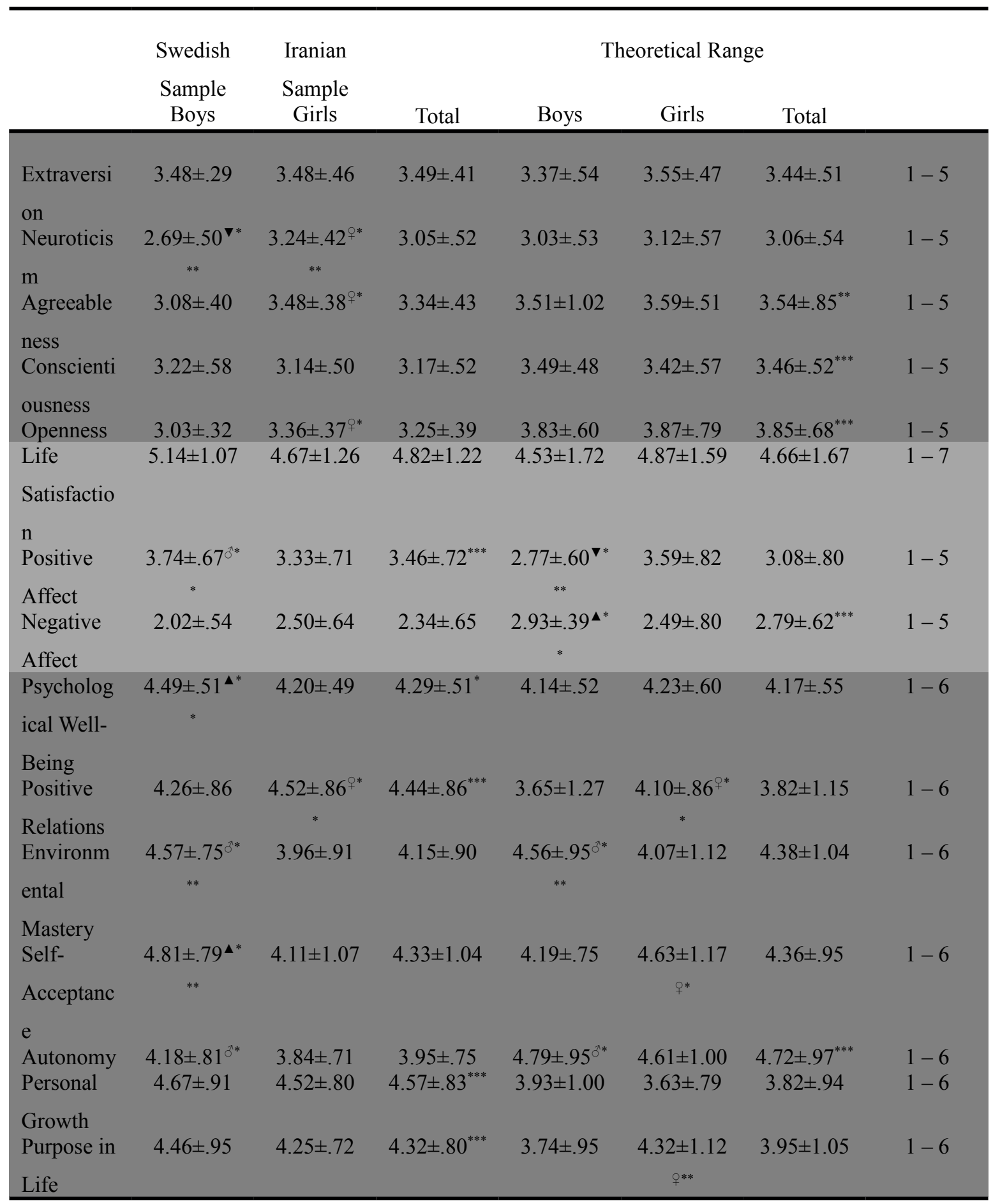

2 Note: ${ }^{*} p<.05,{ }^{* *} p<.01 .{ }^{* * *} p<.001,{ }^{\hat{⿵}}=$ higher than girls, ${ }^{\circ}=$ higher than boys, ${ }^{\mathbf{V}}=$ lower than all groups, ${ }^{\mathbf{\Lambda}}=$ 3 higher than all groups. 


\section{Table 2 (on next page)}

Correlations between personality and well-being variables in the Swedish sample. 
Table 2. Correlations between personality and well-being variables in the Swedish sample.

\begin{tabular}{|c|c|c|c|c|c|c|c|c|c|c|c|c|c|c|c|}
\hline$\stackrel{+}{\underline{\sigma}}$ & 1 & 2 & 3 & 4 & 5 & 6 & 7 & 8 & 9 & 10 & 11 & 12 & 13 & 14 & 15 \\
\hline Extraversion (1) & - & & & & & & & & & & & & & & \\
\hline Neuroticism (2) & $-.35^{* * *}$ & - & & & & & & & & & & & & & \\
\hline Agreeableness (3) & $.14 n s$ & $.17 n s$ & - & & & & & & & & & & & & \\
\hline Conscientiousness (4) & $.25^{* *}$ & $-.26^{* *}$ & $.03 n s$ & - & & & & & & & & & & & \\
\hline Openness (5) & $.08 n s$ & $.25^{* *}$ & $.38^{* * *}$ & $-.08 n s$ & - & & & & & & & & & & \\
\hline Life Satisfaction (6) & $.52^{* * *}$ & $-.49^{* * *}$ & $.11 n s$ & $.21^{*}$ & $-.09 n s$ & - & & & & & & & & & \\
\hline Positive Affect (7) & $.31^{* * *}$ & $-.44^{* * *}$ & $-.18 n s$ & $.27^{* *}$ & $-.17 n s$ & $.45^{* * *}$ & - & & & & & & & & \\
\hline Negative Affect (8) & $-.23^{* *}$ & $.49^{* * *}$ & $-.02 n s$ & $-.18 n s$ & $.21^{*}$ & $-.38^{* * *}$ & $-.32^{* * *}$ & - & & & & & & & \\
\hline Psychological Well-Being ( & $.53^{* * *}$ & $-.63^{* * *}$ & $.03 n s$ & $.52^{* * *}$ & $-.01 n s$ & $.67^{* * *}$ & $.38^{* * *}$ & $-.38^{* * *}$ & - & & & & & & \\
\hline Positive Relations (10) & $.49^{* * *}$ & $-.33^{* * *}$ & $.38^{* * *}$ & $.13 n s$ & $.20 n s$ & $.42^{* * *}$ & $.05 n s$ & $-.19 n s$ & $.57^{* * *}$ & - & & & & & \\
\hline Environmental Mastery (11) & $.44^{* * *}$ & $-.65^{* * *}$ & $-.11 n s$ & $.42^{* * *}$ & $-.18 n s$ & $.49^{* * *}$ & $.51^{* * *}$ & $-.51^{* * *}$ & $.72^{* * *}$ & $.37^{* * *}$ & - & & & & \\
\hline Self-Acceptance (12) & $.53^{* * *}$ & $-.54^{* * *}$ & $.03 n s$ & $.27^{* *}$ & $-.10 n s$ & $.71^{* * *}$ & $.38^{* * *}$ & $-.29^{* *}$ & $.76^{* * *}$ & $.46^{* * *}$ & $.52^{* * *}$ & - & & & \\
\hline Autonomy (13) & $-.07 n s$ & $-.44^{* * *}$ & $-.16 n s$ & $.19 n s$ & $-.04 n s$ & $.15 n s$ & $.06 n s$ & $-.11 n s$ & $.36^{* * *}$ & $-.03 n s$ & $.17 n s$ & $.06 n s$ & - & & \\
\hline Personal Growth (14) & $.32^{* * *}$ & $-.12 n s$ & $.16 n s$ & $.35^{* * *}$ & $.31^{* * *}$ & $.29^{* *}$ & $.15 n s$ & $-.07 n s$ & $.60^{* * *}$ & $.18 n s$ & $.17 n s$ & $.30^{* * *}$ & $.17 n s$ & - & \\
\hline Purpose in Life (15) & $.05 n s$ & $-.09 n s$ & $-.22^{*}$ & $.50^{* * *}$ & $-.21^{*}$ & $.17 n s$ & $.13 n s$ & $-.12 n s$ & $.45^{* * *}$ & $-.07 n s$ & $.21^{*}$ & $.17 n s$ & $.02 n s$ & $.33^{* * *}$ & - \\
\hline
\end{tabular}

Note: $n s=$ nonsignificant; ${ }^{*} p<.05 ;{ }^{* *} p<.01 ;{ }^{* * *} p<.001$. 


\section{Table 3 (on next page)}

Multiple Regressions for the Swedish sample

Personality traits' relationship to subjective well-being and psychological well-being, as well as the relationship between psychological well-being dimensions and subjective well-being. 
1 Table 3. Multiple Regressions for the Swedish sample: personality traits' relationship to

2 subjective well-being and psychological well-being, as well as the relationship between

3 psychological well-being dimensions and subjective well-being.

\begin{tabular}{|c|c|c|c|c|c|c|c|}
\hline $\begin{array}{l}\text { Predictor } \\
\text { Variable }\end{array}$ & $\begin{array}{l}\text { Outcome } \\
\text { Variable }\end{array}$ & $\begin{array}{l}\text { Adj } \\
R^{2}\end{array}$ & $\begin{array}{c}\text { Unst. } \\
\text { B }\end{array}$ & $\begin{array}{c}\text { Unst. } \\
\text { SE }\end{array}$ & Stand. $\beta$ & $F$ & $t$ \\
\hline \multicolumn{8}{|c|}{ Personality Traits } \\
\hline Extraversion (E) & & - & 1.06 & .33 & .34 & - & $3.23^{* * *}$ \\
\hline Neuroticism (N) & $\begin{array}{c}\text { Life } \\
\text { Satisfaction }\end{array}$ & - & -.91 & .26 & -.38 & - & $-3.47^{* * *}$ \\
\hline E, $N$ & & .33 & - & - & - & $8.22^{* * *}$ & - \\
\hline Neuroticism & Positive Affect & .21 & -.45 & .17 & -.32 & 4.82 & $-2.63^{* *}$ \\
\hline Neuroticism & Negative Affect & .23 & .65 & .15 & .53 & 5.23 & $4.30^{* * *}$ \\
\hline Extraversion & & - & .23 & .11 & .18 & - & $2.10^{*}$ \\
\hline Neuroticism & Psychological & - & -.52 & .09 & -.53 & - & $-5.81^{* * *}$ \\
\hline $\begin{array}{l}\text { Conscientiousness } \\
\text { (C) }\end{array}$ & Well-Being & - & .32 & .08 & .33 & - & $4.00^{* * *}$ \\
\hline & & .53 & - & - & - & $18.50^{* * *}$ & - \\
\hline \multicolumn{8}{|l|}{$\mathrm{E}, \mathrm{N}, \mathrm{C}$} \\
\hline Extraversion & & - & .86 & .21 & .41 & - & $4.10^{* * *}$ \\
\hline Neuroticism & Positive & - & -.41 & .17 & -.25 & - & $-2.40^{*}$ \\
\hline Agreeableness (A) & Relations & - & .73 & .20 & .36 & - & $3.65^{* * *}$ \\
\hline $\mathrm{E}, \mathrm{N}, \mathrm{A}$ & & .39 & - & - & - & $11.02^{* * *}$ & - \\
\hline Extraversion & & - & .41 & .19 & .19 & - & $2.14^{*}$ \\
\hline Neuroticism & Environmental & - & -.88 & .16 & -.52 & - & $-5.59^{* * *}$ \\
\hline Conscientiousness & Mastery & - & .39 & .14 & .24 & - & $2.83^{* *}$ \\
\hline $\mathrm{E}, \mathrm{N}, \mathrm{C}$ & & .50 & - & - & - & $16.41^{* * *}$ & - \\
\hline Extraversion & $\begin{array}{l}\text { Self- } \\
\text { Acceptance }\end{array}$ & - & .71 & .27 & .28 & - & $2.61^{* *}$ \\
\hline
\end{tabular}




\begin{tabular}{|c|c|c|c|c|c|c|c|}
\hline Neuroticism & & - & -.90 & .22 & -.44 & - & $-4.04^{* * *}$ \\
\hline $\mathrm{E}, \mathrm{N}$ & & .32 & - & - & - & $8.10^{* * *}$ & - \\
\hline Extraversion & & - & -.44 & .20 & -.24 & - & $-2.15^{*}$ \\
\hline Neuroticism & Autonomy & - & -.73 & .17 & -.51 & - & $-4.40^{* * *}$ \\
\hline $\mathrm{E}, \mathrm{N}$ & & .22 & - & - & - & $5.45^{* * *}$ & - \\
\hline Conscientiousness & & - & .46 & .16 & .29 & - & $2.82^{* *}$ \\
\hline Openness $(\mathrm{O})$ & $\begin{array}{l}\text { Personal } \\
\text { Growth }\end{array}$ & - & .97 & .25 & .46 & - & $3.94^{* * *}$ \\
\hline $\mathrm{C}, \mathrm{O}$ & & .23 & - & - & - & $5.70^{* * *}$ & - \\
\hline Conscientiousness & Purpose in Life & .24 & .74 & .16 & .49 & 5.81 & $4.76^{* * *}$ \\
\hline
\end{tabular}

Psychological Well-Being

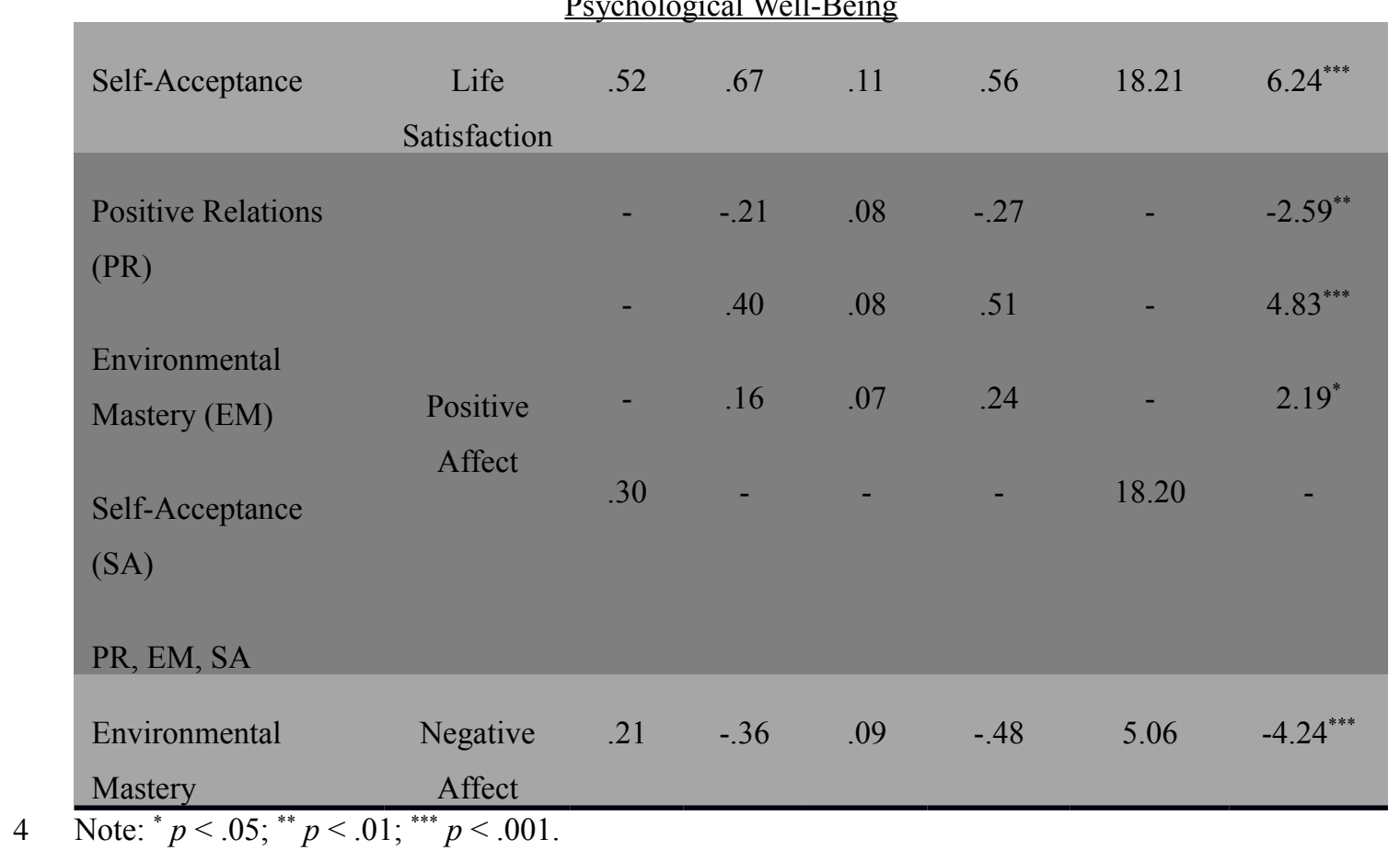




\section{Table 4 (on next page)}

Correlations between personality and well-being variables in the Iranian sample. 
Table 4. Correlations between personality and well-being variables in the Iranian sample.

\begin{tabular}{|c|c|c|c|c|c|c|c|c|c|c|c|c|c|c|c|}
\hline 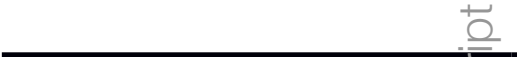 & 1 & 2 & 3 & 4 & 5 & 6 & 7 & 8 & 9 & 10 & 11 & 12 & 13 & 14 & 15 \\
\hline Extraversion (1) & - & & & & & & & & & & & & & & \\
\hline Neuroticism (2) & $-.09 n s$ & - & & & & & & & & & & & & & \\
\hline Agreeableness (3) & $.11 n s$ & $.10 n s$ & - & & & & & & & & & & & & \\
\hline Conscientiousness (4) & $.18^{*}$ & $.32^{* * * *}$ & $.08 n s$ & - & & & & & & & & & & & \\
\hline Openness (5) & $.43^{* * *}$ & $.15 n s$ & $.04 n s$ & $.38^{* * *}$ & - & & & & & & & & & & \\
\hline Life Satisfaction (6) & $.18^{*}$ & $-.19^{*}$ & $-.01 n s$ & $.17 n s$ & $.26^{* *}$ & - & & & & & & & & & \\
\hline Positive Affect (7) & $.26^{* *}$ & $-.01 n s$ & $.10 n s$ & $-.02 n s$ & $.25^{* *}$ & $.08 n s$ & - & & & & & & & & \\
\hline Negative Affect (8) & $.07 n s$ & $.24^{* *}$ & $.01 n s$ & $.19^{*}$ & $.18^{*}$ & $-.07 n s$ & $-.03 n s$ & - & & & & & & & \\
\hline Psychological Well-Being (9) & $.11 n s$ & $.03 n s$ & $-.07 n s$ & $.11 n s$ & $.16 n s$ & $.19^{*}$ & $.18^{*}$ & $-.18^{*}$ & - & & & & & & \\
\hline Positive Relations (10) & $-.12 n s$ & $.11 n s$ & $-.03 n s$ & $-.05 n s$ & $-.00 n s$ & $-.08 n s$ & $.03 n s$ & $-.18^{*}$ & $.53^{* * *}$ & - & & & & & \\
\hline Environmental Mastery (11) & $-.03 n s$ & $-.13 n s$ & $-.11 n s$ & $.07 n s$ & $-.02 n s$ & $.09 n s$ & $-.02 n s$ & $.00 n s$ & $.56^{* * *}$ & $.01 n s$ & - & & & & \\
\hline Self-Acceptance (12) & $.21^{* *}$ & $-.10 n s$ & $-.07 n s$ & .08 & $.26^{* *}$ & $.38^{* * *}$ & $.31^{* * *}$ & $-.18 n s$ & $.54^{* * *}$ & $.11 n s$ & $.15 n s$ & - & & & \\
\hline Autonomy (13) & $.20^{*}$ & $.15 n s$ & .14 & $.19^{*}$ & $.11 n s$ & $.08 n s$ & $.10 n s$ & $-.12 n s$ & $.50^{* * *}$ & $.00 n s$ & $.20^{*}$ & $.16 n s$ & - & & \\
\hline Personal Growth (14) & $.18^{*}$ & $.08 n s$ & $-.05 n s$ & $.13 n s$ & $.04 n s$ & $-.06 n s$ & $.05 n s$ & $.15 n s$ & $.49^{* * *}$ & $.09 n s$ & $.17 n s$ & $.10 n s$ & $.14 n s$ & - & \\
\hline Purpose in Life (15) & $.11 n s$ & $-.02 n s$ & $-.10 n s$ & $-.04 n s$ & $.20^{*}$ & $.22^{* *}$ & $.13 n s$ & $-.25^{* *}$ & $.63^{* * *}$ & $.30^{* * *}$ & $.23^{* *}$ & $.29^{* * *}$ & $.14 n s$ & $.03 n s$ & - \\
\hline
\end{tabular}

Note: $n s=$ nonsignificant; ${ }^{*} p<.05 ;{ }^{* *} p<.01 ;{ }^{* * *} p<.001$. 


\section{Table 5 (on next page)}

Multiple Regressions for the Iranian sample

Personality traits' relationship to subjective well-being and psychological well-being, as well as the relationship between psychological well-being dimensions and subjective well-being. 
1 Table 5. Multiple Regressions for the Iranian sample: personality traits' relationship to subjective

2 well-being and psychological well-being, as well as the relationship between psychological well-

3 being dimensions and subjective well-being.

\begin{tabular}{|c|c|c|c|c|c|c|c|}
\hline $\begin{array}{l}\text { Predictor } \\
\text { Variable }\end{array}$ & $\begin{array}{l}\text { Outcome } \\
\text { Variable }\end{array}$ & $\operatorname{Adj} R^{2}$ & Unst. B & Unst. SE & Stand. $\beta$ & $F$ & $t$ \\
\hline \multicolumn{8}{|c|}{ Personality Traits } \\
\hline Neuroticism $(\mathrm{N})$ & & - & -.80 & .30 & -.26 & - & $-2.72^{* *}$ \\
\hline Openness (O) & $\begin{array}{c}\text { Life } \\
\text { Satisfaction }\end{array}$ & - & .55 & .28 & .21 & - & $1.98^{*}$ \\
\hline $\mathrm{N}, \mathrm{O}$ & & .14 & - & - & - & $3.44^{* *}$ & - \\
\hline Openness & Positive Affect & .13 & .26 & .13 & .21 & 2.74 & $1.97^{*}$ \\
\hline Neuroticism & $\begin{array}{c}\text { Negative } \\
\text { Affect }\end{array}$ & .10 & .24 & .11 & .20 & 2.14 & $2.07^{*}$ \\
\hline Extraversion & $\begin{array}{l}\text { Personal } \\
\text { Growth }\end{array}$ & .07 & .41 & .20 & .22 & 1.30 & $2.03^{*}$ \\
\hline Openness & $\begin{array}{c}\text { Purpose in } \\
\text { Life }\end{array}$ & .06 & .37 & .19 & .23 & 1.43 & $2.02^{*}$ \\
\hline
\end{tabular}

Psychological Well-Being

\begin{tabular}{lccccccc} 
Self-Acceptance & $\begin{array}{c}\text { Life } \\
\text { Satisfaction }\end{array}$ & .16 & .56 & .18 & .32 & 2.87 & $3.22^{* *}$ \\
& & & & & & & \\
Self-Acceptance & Positive Affect & .13 & .26 & .09 & .30 & 2.29 & $3.02^{* *}$ \\
\hline
\end{tabular}

4 Note: ${ }^{*} p<.05 ;{ }^{* *} p<.01$. 